\title{
Investigation of the Relation between Rolling Contact Fatigue Property and Microstructure on the Surface Layer of D2 Wheel Steel
}

\author{
Shuaishuai Wang1, Xiujuan Zhao',2, Pengtao Liu1,2, Jinzhi Pan',2, Chunhuan Chen"1,2, \\ Ruiming Ren ${ }^{1,2 *}$ \\ ${ }^{1}$ School of Materials Science and Engineering, Dalian Jiaotong University, Dalian, China \\ ${ }^{2}$ Key Laboratory of Critical Materials of Rail Transportation in Liaoning Province, Dalian Jiaotong University, Dalian, China \\ Email: *rm ren@djtu.edu.cn
}

How to cite this paper: Wang, S.S., Zhao, X.J., Liu, P.T., Pan, J.Z., Chen, C.H. and Ren, R.M. (2019) Investigation of the Relation between Rolling Contact Fatigue Property and Microstructure on the Surface Layer of D2 Wheel Steel. Materials Sciences and Applications, 10, 509-526.

https://doi.org/10.4236/msa.2019.108037

Received: June 19, 2019

Accepted: August 5, 2019

Published: August 8, 2019

Copyright () 2019 by author(s) and Scientific Research Publishing Inc. This work is licensed under the Creative Commons Attribution International License (CC BY 4.0).

http://creativecommons.org/licenses/by/4.0/

\begin{abstract}
Through the rolling contact fatigue experiment under the condition of the lubricating oil, this article investigated the relation between contact fatigue property and microstructure on the surface layer of D2 wheel steel. The results showed that although the roughness of the original specimen induced by mechanical processing would diminish to some extent in the experiment, the $0.5-1.5 \mu \mathrm{m}$ thick layer of ultrafine microstructure on the original mechanically-processed specimen surface would still become micro-cracks and small spalling pits due to spalling, and would further evolve into fatigue crack source. Additionally, even under the impact of the load that was not adequate to make the material reach fatigue limit, the ferrite in the microstructure underwent plastic deformation, which led the refinement of proeutectoid ferrite grains. During the experiment, the hardening and the refinement caused by plastic deformation consisted with the theory that dislocation gave rise to plastic deformation and grain refinement. The distribution laws of hardness and ferrite grain sizes measured could be explained by the distribution law of the shearing stress in the subsurface.
\end{abstract}

\section{Keywords}

D2 Wheel Steel, Rolling Contact Fatigue Property, Microstructure Evolution of the Surface Layer, The Formation and Propagation of Contact Fatigue Cracks

\section{Introduction}

Due to the operational cyclic loading at the wheel-rail interface, contact fatigue 
damage appears and can lead to the spalling of the wheel/rail surface-even catastrophic failure sometimes. With the rapid advancement of the high-speed and heavy-haul railway, the wheel-rail contact fatigue that threatens operation safety has attracted experts' attention more often [1] [2] [3].

Rolling contact fatigue failure of wheel/rail materials is a complicated process, and many factors affect the rolling contact fatigue life of wheel/rail materials. It is currently acknowledged that the mechanism of wheel-rail contact fatigue is that fatigue cracks [4] initiate because plastic deformation caused by ratcheting effect accumulates and reaches the ductility limits of wheel/rail materials. Rains, snows, water or oil will generate hydrodynamic pressure inside these cracks and reduce the friction on their surface, thus accelerating the propagation of fatigue cracks [5] [6] [7] [8] [9]. Surface roughness can result in high contact strain [10], and the stress around roughness peaks is 8 times higher than Hertzian contact stress under ideally smooth condition.

Fatigue failure formed on the friction surface is related to the microstructure of the material. White etching layers on the wheel-rail friction surface exert immense influences on the initiation and propagation of fatigue cracks and the subsequent spalling at the wheel-rail contact interface [11] [12] [13] [14]. The research results of Chen [14] and others reveal that the white etching layers formed through local laser quenching will accelerate the formation of fatigue cracks. Lian and others [15] conclude that the formation of white etching layers will speed up crack formation and failure of wheel/rail materials. Nevertheless, relative investigations into the impacts of the damaged layer of wheel/rail materials induced by mechanical processing during the process of contact fatigue haven't been that detailed [16] [17] [18].

This present paper is investigating the contact fatigue property of D2 highspeed wheel steel by using rolling fatigue tester. It investigates the relationship between the initiation of fatigue cracks and the deformed microstructure induced by mechanical processing at the outermost layer, and analyzes the evolution of the microstructure in the subsurface during the process of contact fatigue. The aim of the current paper is to provide references for further study on the contact fatigue of actual wheel/rail materials and design and processing of material compositions.

\section{Experimental Materials and Methods}

The experimental material was D2 wheel steel. Its main chemical compositions were as follows: $0.53 \% \mathrm{C}, 1.0 \% \mathrm{Si}$ and $1.0 \% \mathrm{Mn}$. The experiment was performed on the GPM-30 rolling contact fatigue tester. The actual wheel-rail contact state was simulated by rolling the two-disc specimens, which followed the procedures in YB/T 5345-2014 Metallic Materials-Rolling Contact Fatigue Test [19]. The outer diameters of the main and accompanying specimen were both $60 \mathrm{~mm}$, the width and the height of the protruding part of the main specimen were $5 \mathrm{~mm}$ and $3 \mathrm{~mm}$ respectively, while the width of the accompanying specimen was 20 $\mathrm{mm}$, seen in Figure 1 . 

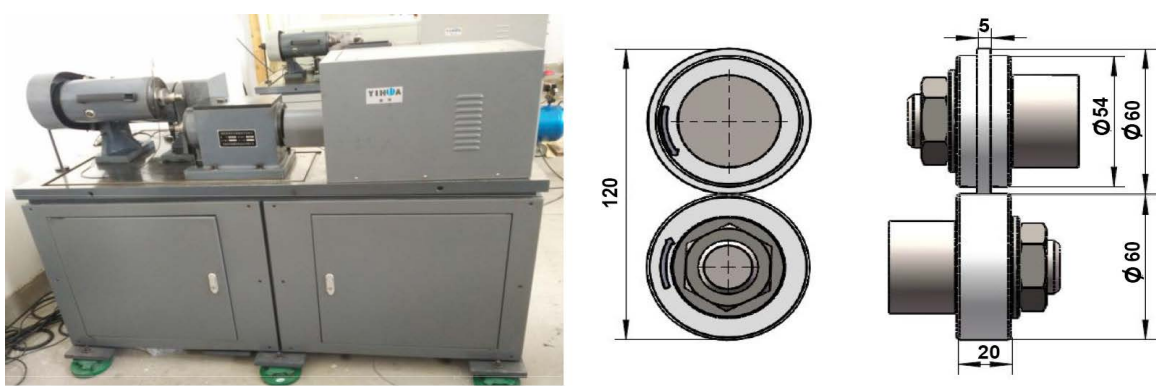

Figure 1. GPM-30 rolling contact fatigue tester and the contact mode of the main and accompanying specimens.

D2 and U71Mn steel, selected as the materials for wheel and rail specimens respectively, were both forged and heat-treated so that they had the similar microstructure and hardness as the actual wheels and rails. The hardness of the D2 steel specimen gained was $255 \mathrm{HV}-265 \mathrm{HV}$, and the hardness of the U71Mn steel specimen was $295 \mathrm{HV}$ - $305 \mathrm{HV}$. The microstructure of both specimens consisted of lamellar pearlite and proeutectoid ferrite; however, less proeutectoid ferrite existed in the U71Mn steel.

According to the rolling angular velocity of high-speed trains at the speed of $250 \mathrm{mph}$ and $0.5 \%$ of slip ratio, the rotation speeds of the main and accompanying specimens were set at $1440 \mathrm{r} / \mathrm{min}$ and $1446 \mathrm{r} / \mathrm{min}$ respectively. Based on Hertz Contact Theory [20], the maximum actual wheel-rail contact stress caused by 17-ton axle load was $1147 \mathrm{MPa}$. In the experiment, six groups of contact stresses were selected as follows: $1200 \mathrm{MPa}, 1250 \mathrm{MPa}, 1300 \mathrm{MPa}, 1350 \mathrm{MPa}$, $1400 \mathrm{MPa}$ and $1450 \mathrm{MPa}$. Then each stress was tested with four sets of specimens. The contact surface of the main and accompanying specimen was constantly lubricated by No. 20 engine oil. When spalling pits that were equal to or larger than $3 \mathrm{~mm}^{2}$ appeared on the specimen surface, fatigue failure could be determined. Subsequently, the Universal Serial Bus test microscope with 300X magnification was utilized to record the macro-morphology of fatigue damage; then SUPRA 55 field emission scanning electron microscope (SEM) was employed to observe the damage morphology of the specimen surface and the microstructure of the surface layer, and FM-700 micro-hardness tester was used to measure the hardness of the specimen surface, with the load of $25 \mathrm{~g}$ and the duration of $15 \mathrm{~s}$. The hardness at different depth of the cross-section was the average value calculated by the hardness measured from five points selected at the same depth. The first depth was $20 \mu \mathrm{m}$ from the surface, and was increased with an increment of $10 \mu \mathrm{m}$. The surface hardness was the average value acquired by 10 points randomly selected along the direction perpendicular to the contact surface after mechanical polishing.

\section{Results}

\subsection{The S-N Curve of D2 Wheel Steel}

Table 1 showed the experimental results of the $\mathrm{D} 2$ wheel steel rolling contact fatigue property: when the contact stress was lower than $1300 \mathrm{MPa}$, the fatigue life 
Table 1. Fatigue life of the specimen under different contact stress.

\begin{tabular}{ccccc}
\hline \multirow{2}{*}{$\begin{array}{c}\text { Contact } \\
\text { Stress/MPa }\end{array}$} & \multicolumn{4}{c}{ Fatigue life/10 ${ }^{4} \mathrm{r}$} \\
\cline { 2 - 5 } 1200 & $>1000$ & $>1000$ & 3 & 4 \\
\hline 1250 & $>1000$ & $>1000$ & $>1000$ & $>1000$ \\
1300 & 579.3 & 890.6 & $>1000$ & $>1000$ \\
1350 & 432.6 & 669.9 & 713.6 & $>1000$ \\
1400 & 149.4 & 263.8 & 306.9 & 813.8 \\
1450 & 52.9 & 96.42 & 97.8 & 528.7 \\
\hline
\end{tabular}

of the specimens was larger than $1 \times 10^{7}$ rotations; when the contact stress was $1300 \mathrm{Mpa}$, the fatigue life of the two specimens out of the four did not reach $1 \times$ $10^{7}$ rotations; when the fatigue stress was larger than $1300 \mathrm{Mpa}$, the fatigue life of all four specimens did not amount to $1 \times 10^{7}$ rotations.

Figure 2 displayed the relation between the contact stress and the fatigue life in the logarithmic coordinate system. The least-square method was adopted to calculate the fitting curve equation with the data, through which the S-N curve of D2 wheel steel was acquired:

$$
S=2343.762-150.536 \lg N
$$

In Equation (1), $\mathrm{S}$ represented the contact stress (MPa), and $N$ signified rotations. When $N=1 \times 10^{7}$ was put into the above-mentioned equation, the fatigue limit of the D2 wheel steel was $1290 \mathrm{Mpa}$.

\subsection{Fatigue Spalling Damage}

Macroanalysis was initially conducted on the fatigue spalling of the specimen surface under contact fatigue. The results indicated that great amounts of $\mathrm{V}$-shaped spalling appeared on the specimen surface and small amounts of pox-like or irregular-shaped spalling also existed, shown in Figure 3. V-shaped spalling was also known as arrow-shaped spalling, whose apex angle oriented towards the rolling direction of the specimen. Through statistics, the degree of the apex angle was between $70^{\circ}$ and $140^{\circ}$. According to the morphology of the fracture surface, the fatigue cracks radiated from the V-shaped tip and propagated towards the opposite to the rolling direction. Then the specimen was cut from the center of the $\mathrm{V}$-shaped spalling along the rolling direction of the specimen, and what was found was that the depth of the cracks reached about 1.2 $\mathrm{mm}$. According to the results of the experimental statistics, the angle between the propagation direction of this type of main fatigue cracks and the surface was between $30^{\circ}$ and $45^{\circ}$. On the side of the main cracks close to the worn surface, the secondary cracks almost perpendicular to the main cracks were initiated and expanded towards the contact surface, resulting in fatigue spalling after they reached the surface, shown in Figure 4. 


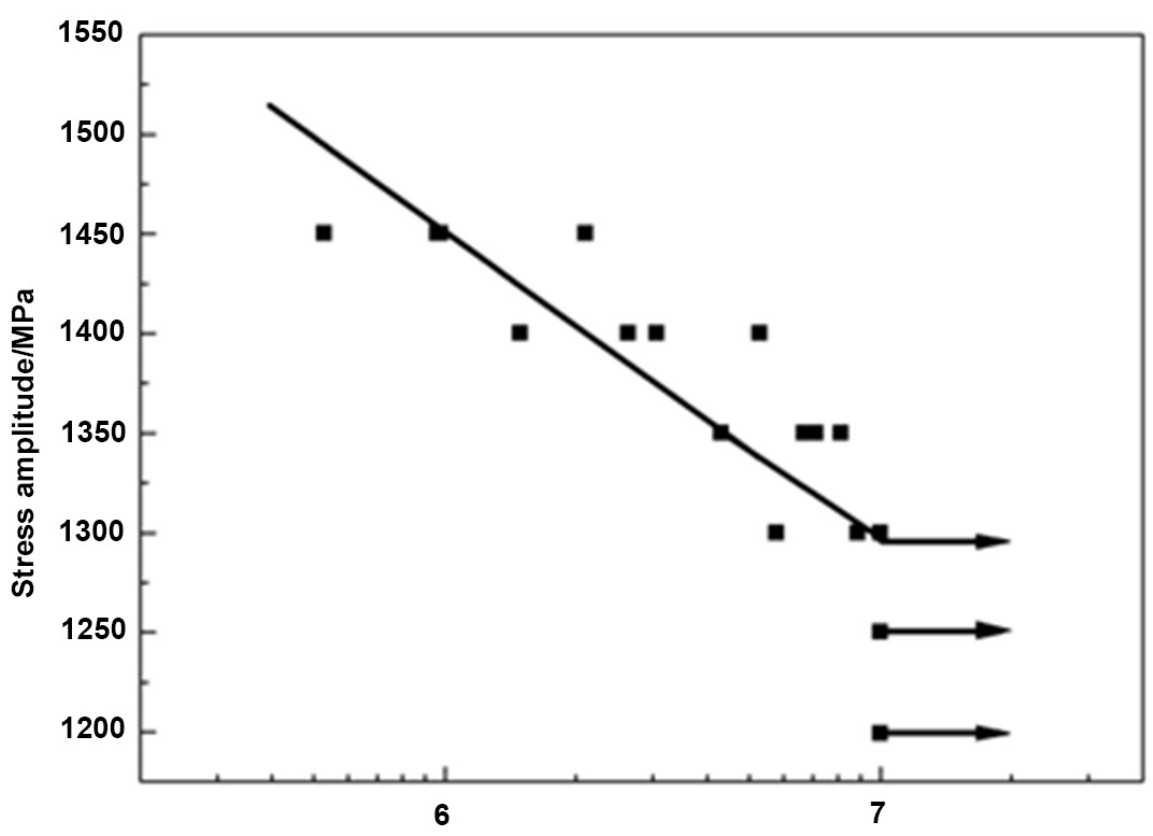

No. of cycles to failure/lgN

Figure 2. S-N curve of D2 wheel steel.
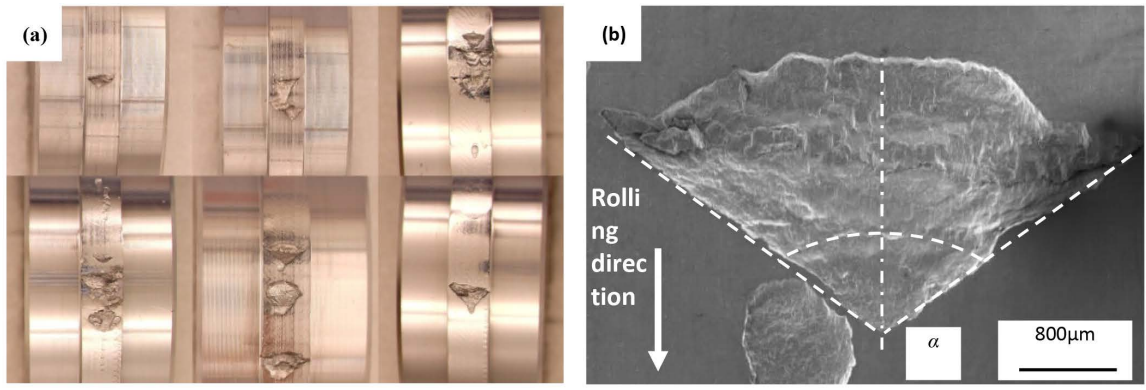

Figure 3. Macrographs of contact fatigue specimen.

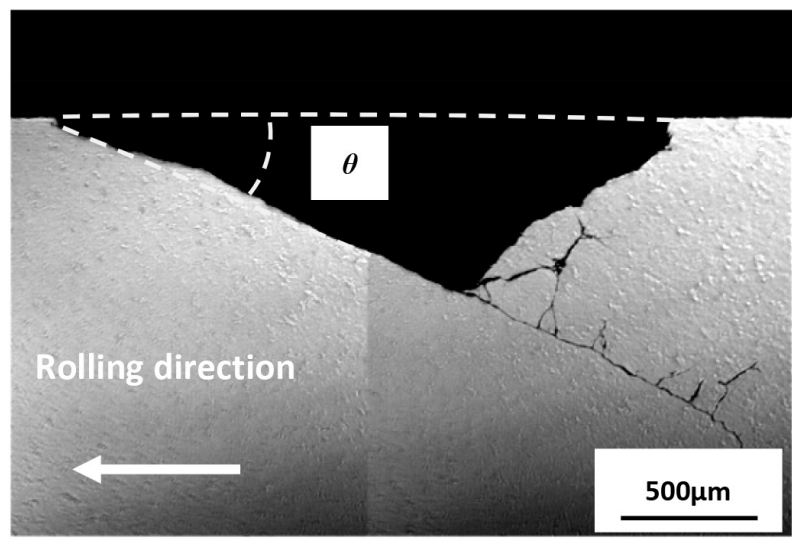

Figure 4. Cross section macrographs of V-shaped fatigue spalling.

In view of the feature that $\mathrm{V}$-shaped fatigue spalling generally originates from rolling contact fatigue spalling [17], the surface morphology of the contact fati- 
gue specimen was thoroughly analyzed in the research. Compared with that of the surface of the original mechanically-processed specimen, the roughness of the specimen surface was diminished after the initial stage of the rolling contact fatigue experiment. This indicated that even under the lubricating condition, protruding points on the surface would be worn smooth during the process of rolling contact fatigue.

Through comprehensive analyses of morphology variations of the specimen surface with fatigue spalling and careful observation of the cross section and longitudinal section under microscope (shown in Figure 4), the formation and propagation process of fatigue cracks could be divided into four stages: the first stage was featured by the appearance of microcracks and small spalling pits on the surface(Figure 5(b)); the second stage was that, under the combined action of the contact stress and the hydrodynamic pressure of lubricating oil, these cracks would propagate along the direction parallel to the surface damage layer caused by mechanical processing and then formed the shallow spalling (the depth was commonly about $1 \mu \mathrm{m}$ ), and even turned into deep cracks that formed certain angles with the contact surface (shown in Figure 5(c)); the third stage was that the deep cracks further propagated and formed the typical V-shaped cracks on the surface (Figure 5(d)); the fourth stage was that after the formation of $\mathrm{V}$-shaped cracks, the secondary cracks along the direction roughly perpendicular to the main cracks were formed, then propagated towards the surface and finally caused V-shaped spalling (Figure 5(e)).

In the analysis of the path along which the cracks propagated, it was discovered that fatigue cracks preferentially grew towards the proeutectoid ferrite, and then propagated along the interface between the proeutectoid ferrite and pearlitic colony (Figure 6(a)). In certain areas where cracks penetrated pearlite, what could be observed was that pearlite on both sides of the cracks was twisted due to plastic deformation.

\subsection{The Analysis of the Surface Microstructure}

In order to investigate the formation of contact fatigue cracks on the surface and its relationship with the surface microstructure, slight polishing and etching was firstly conducted on the surface of the original mechanically-processed specimen and the surface of the failure specimen, and then SEM was employed to observe both of them. Figure 7(a) and Figure 7(b) displayed the surface morphology and the microstructure on the surface layer of the original mechanically-processed specimen. It could be found that the surface of the original mechanically-processed specimen was characterized by the rough morphology like peaks and valleys. Inside the microstructure from the longitudinal and cross sections on the surface, what could be spotted was that on the mechanically-processed surface did exist a layer of ultrafine microstructure, with the thickness of $0.5-1.5 \mu \mathrm{m}$. The thickness of the layer at the peak of the surface was higher than that of the layer at the valley (displayed in Figure 7(b)). 

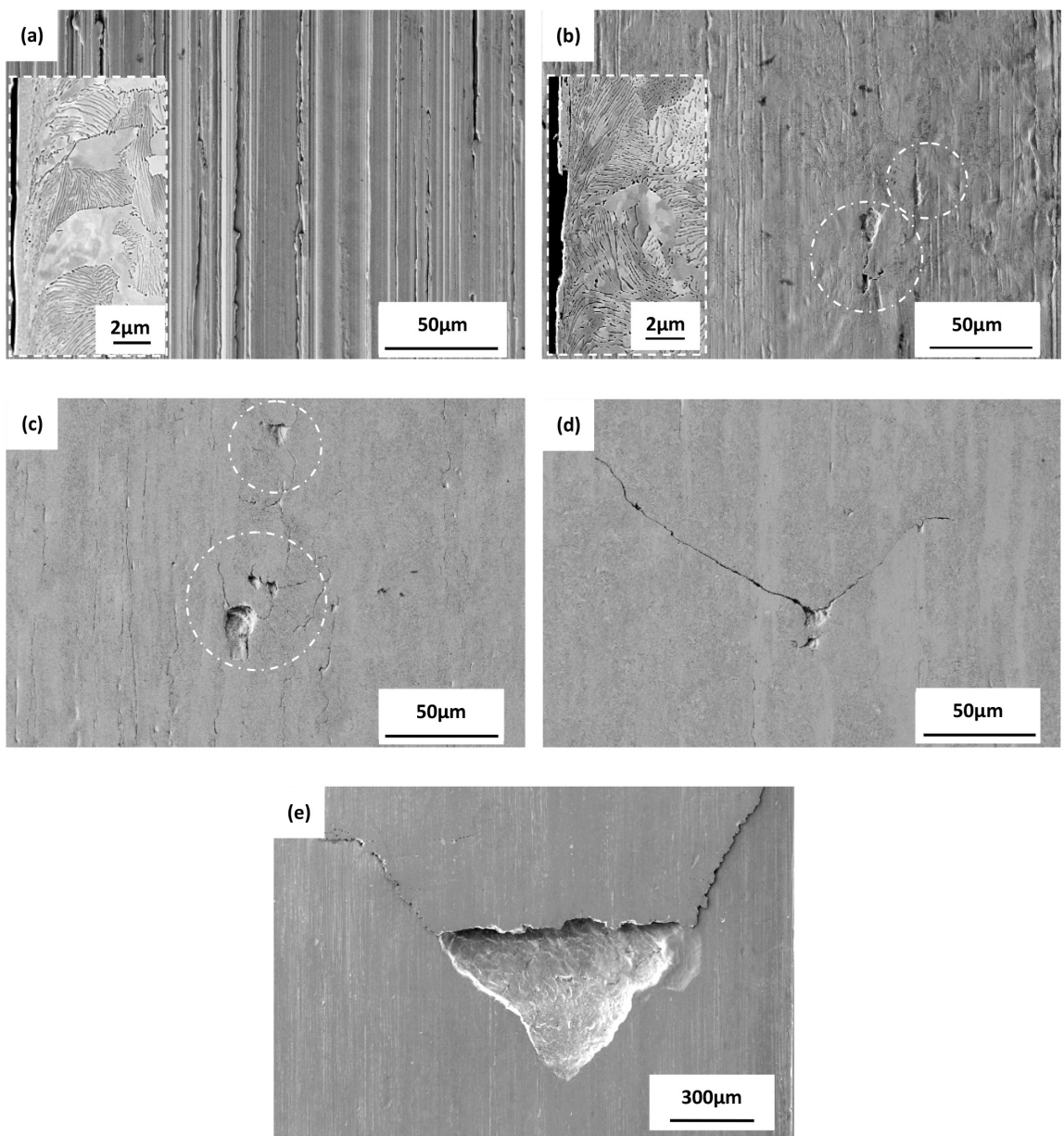

Figure 5. The Damage Process of the Rolling Contact Fatigue Surface. (a) The Surface of the Original Mechanically-processed Specimen and the Metallography of the Longitudinal Section; (b) Surface Micro-damage of the Fatigue Specimen and the Metallography of the Longitudinal Section; (c) The Initiation Stage of Fatigue Cracks; (d) The Propagation Stage of Fatigue Cracks; (e) The Formation of Fatigue Spalling.
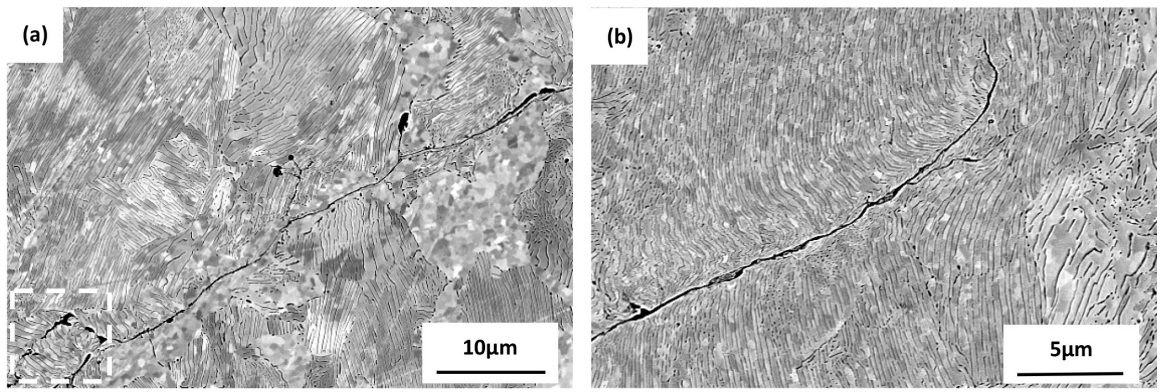

Figure 6. The Microstructure at the Tip of Crack Propagation in ferrite (a) and in pearlite (b).

Through analyses of the microstructure from the surface to the central part of the specimen after contact fatigue experiment, it was discovered that apart from the thin layer of ultrafine microstructure that still remained on the surface layer of the original mechanically-processed specimen, proeutectoid ferrite grains 

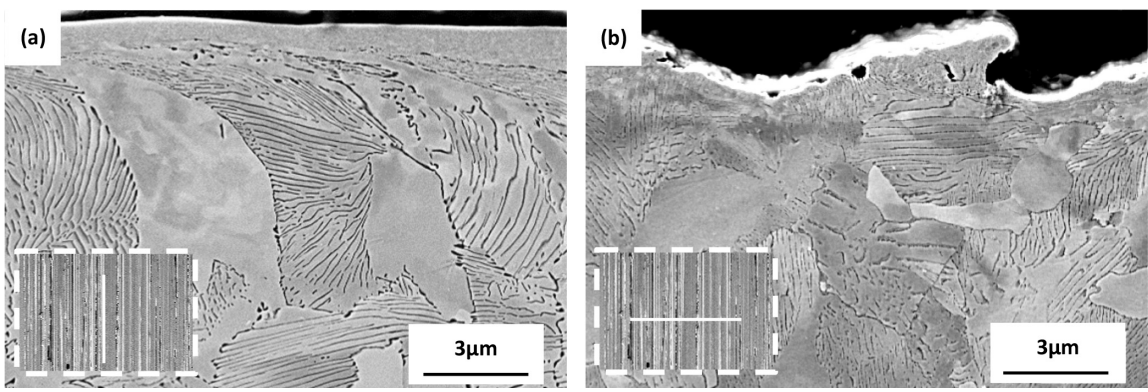

Figure 7. The morphology and microstructure on the contact surface of the original mechanically-processed specimen (a) The microstructure of the longitudinal section and the surface morphology of the original mechanically-processed specimen, (b) The microstructure of the cross section and the surface morphology of the original mechanically-processed specimen.

varied obviously with the increasing depths: as depths increased, grains were refined step by step; when the depth reached about $200 \mu \mathrm{m}$, the grains were the smallest, and then gradually recovered to the size of the original microstructure again, as was seen in Figure 8. Figure 9 showed the microstructure at the depth $200 \mu \mathrm{m}$ from the surface of the specimen on which contact fatigue failure did not appear after $1 \times 10^{7} \mathrm{r}$ under the load of $1200 \mathrm{MPa}$. It could be seen that compared with the original central microstructure, proeutectoid ferrite was refined obviously, while the contrast between ferrite subgrains inside lamellar pearlite was enlarged-signifying that the misorientation between each subgrain was increased and the refinement of ferrite subgrains was not that obvious.

\subsection{Hardness Variations of the Surface Layer}

Microhardness measurements were done from the surface to the central part of the original mechanically-processed specimen and the specimens that had gone through the contact fatigue experiment under different contact stresses, and the results were shown in Figure 10. From Figure 10, it could be concluded that on the surface layer of the original mechanically-processed specimen existed a thin layer of ultrafine microstructure (seen from Figure 7), with the thickness of approximately $0.5-1.5 \mu \mathrm{m}$. The hardness of the surface was about $400-450 \mathrm{HV}$, apparently higher than that of the central part $(255-265 \mathrm{HV})$. Under different contact stresses, the materials at certain depths from the surface were hardened with different degrees; however, the hardening laws were the same-the maximum hardness appeared in the subsurface (approximately $200 \mu \mathrm{m}$ from the surface); with the increment of contact stress, both of the depth at which the maximum hardness appeared and the depth of hardening layer were increased, and the hardening degree was also on a rise. When contact stress rose from 1200 $\mathrm{Mpa}$ to $1450 \mathrm{Mpa}$, the maximum hardness of the subsurface changed from 382 $\mathrm{HV}$ to $420 \mathrm{HV}$, respectively located at the depth of $190 \mu \mathrm{m}$ and $240 \mu \mathrm{m}$; at the same time, the depth of the hardening layer gradually increased from $650 \mu \mathrm{m}$ to $1000 \mu \mathrm{m}$. Additionally, it was rather remarkable that although the specimens had 

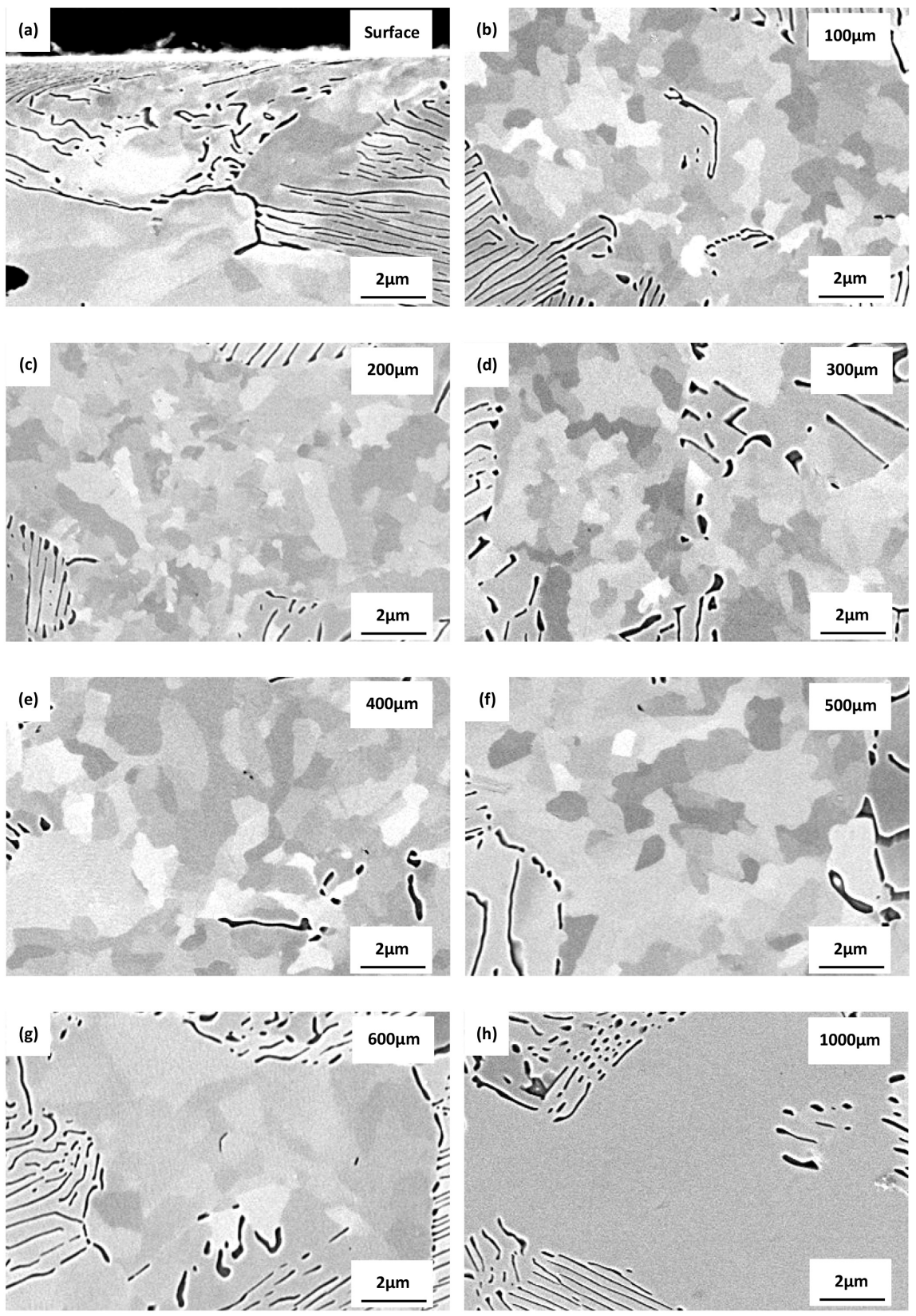

Figure 8. Microstructure Variations of Proeutectoid Ferrite at different depths from the surface of the specimen with contact fatigue (After $1 \times 10^{7} \mathrm{r}$ under the load of $1200 \mathrm{MPa}$ ).
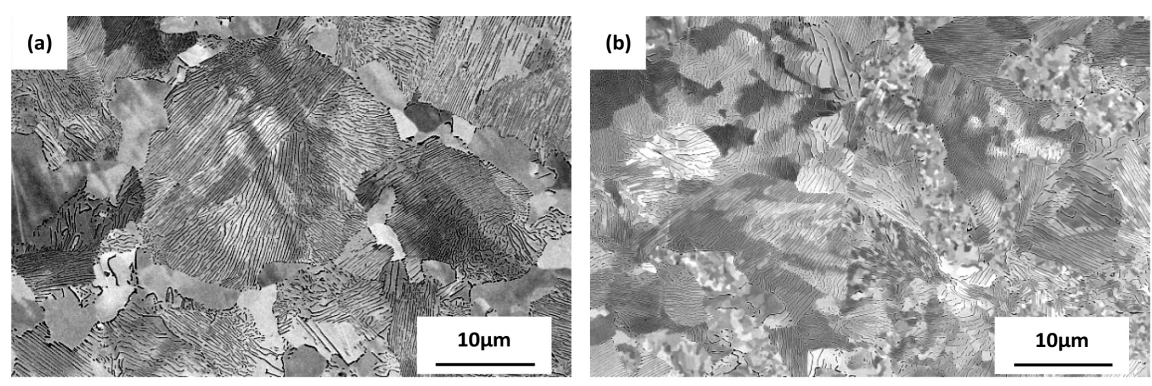

Figure 9. The Original Microstructure (a) and the Microstructure of the Specimen's Surface Layer (b) after $1 \times 10^{7} \mathrm{r}$ with the load of $1200 \mathrm{Mpa}$. 


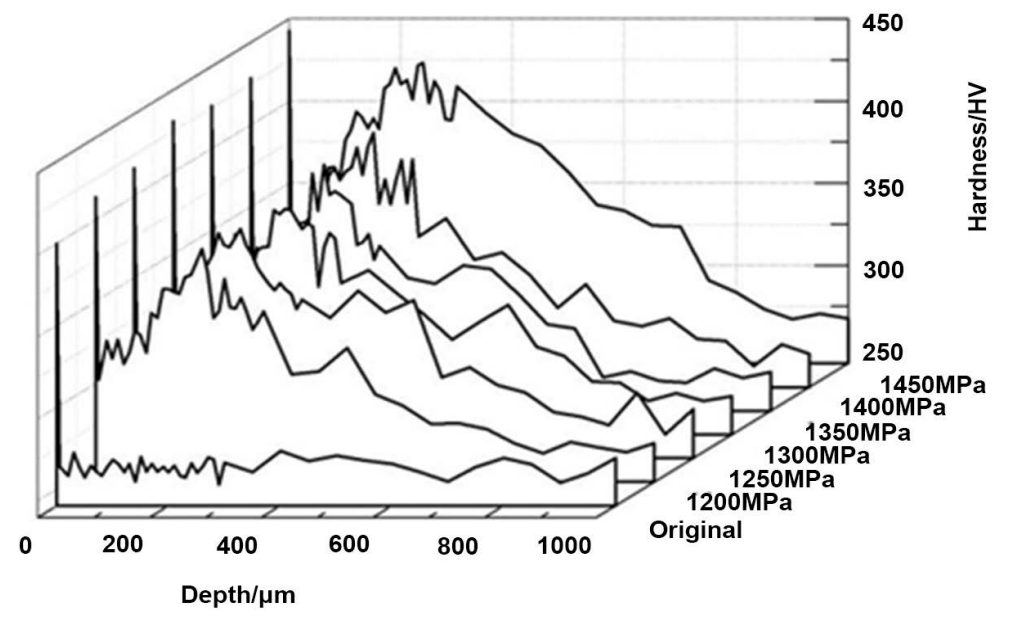

Figure 10. Hardness distribution of the surface layer.

not shown obvious signs of fatigue under the experimental conditions of 1200 $\mathrm{MPa}$ and $1250 \mathrm{Mpa}$, the surface layer also experienced the hardening process.

\section{Discussions}

\subsection{The Distribution of Shear Stress on the Surface}

To discuss the reasons why the surface microstructure and its hardness varied, the distribution of shear stress had been calculated. Based on Hertz Contact Theory [20], the maximum contact stress $P_{0}$ and contact half width $\alpha$ in the contact region of the main and accompanying specimens were as follows:

$$
\begin{aligned}
& p_{0}=\sqrt{\frac{F}{\pi L}\left\{\frac{\frac{1}{\rho_{1}}+\frac{1}{\rho_{2}}}{\frac{1-v_{1}^{2}}{E_{1}}+\frac{1-v_{2}^{2}}{E_{2}}}\right\}} \\
& \left.a=\sqrt{\frac{4 F}{\pi L}\left\{\frac{\frac{1-v_{1}^{2}}{E_{1}}+\frac{1-v_{2}^{2}}{E_{2}}}{\frac{1}{\rho_{1}}+\frac{1}{\rho_{2}}}\right\}}\right\}
\end{aligned}
$$

In the formulas, $P_{0}$ represented the maximum contact stress (MPa); $\pi$ equaled 3.1416; $L$ was the contact length of the specimen, and in this experiment, $L 5$ $\mathrm{mm} ; F$ was the load $(\mathrm{N})$ exerted on the specimen; $V_{1}$ and $V_{2}$ were Poisson's ratios of the upper and lower specimens, $V_{1}=V_{2}=0.3 ; \rho_{1}, \rho_{2}$ were the radii of curvature of the upper and lower specimens, $\rho_{1}, \rho_{2}=30 \mathrm{~mm} ; E_{1}$ and $E_{2}$ were the modulus of elasticity of the upper and lower specimens, $E_{1}=E_{2}=206 \mathrm{GPa} ; \alpha$ was contact half width $(\mu \mathrm{m})$. Then the data and the maximum contact stress of the design $\left(P_{0}\right)$ were put into formulas (2) and (3), and the load of the specimen (F) and the contact half width $(\alpha)$ could be calculated and gained, shown in Table 2 .

The tangential force $q$ on the surface caused by slip ratio could be acquired through Amonton Law: 
Table 2. Experimental load, the maximum contact stress and contact half width.

\begin{tabular}{ccc}
\hline Contact stress $(\mathrm{MPa})$ & Experimental load $\mathrm{F},(\mathrm{N})$ & Contact half width $a,(\mu \mathrm{m})$ \\
\hline 1200 & 2998 & 318 \\
1250 & 3252 & 331 \\
1300 & 3518 & 344 \\
1350 & 3794 & 357 \\
1400 & 4081 & 371 \\
1450 & 4376 & 384 \\
\hline & &
\end{tabular}

In the formula, $\mu$ was the friction parameter, and in the experiment different values of contact stress all approximated 0.1.

Under the combined impacts of positive force and tangential force, the shear stress [21] beneath the contact surface was:

$$
\tau_{1}=\frac{1}{2}\left[\left(\sigma_{x}-\sigma_{z}\right)^{2}+4 \tau_{x z}^{2}\right]^{1 / 2}
$$

In the formula, $\sigma_{x}, \sigma_{z z}, \tau_{x z}$ were stress components respectively under the combined impacts of positive force and tangential force:

$$
\left\{\begin{array}{l}
\sigma_{x}=\left(\sigma_{x}\right)_{p}+\left(\sigma_{x}\right)_{q} \\
\sigma_{z}=\left(\sigma_{z}\right)_{p}+\left(\sigma_{z}\right)_{q} \\
\tau_{x z}=\left(\tau_{x z}\right)_{p}+\left(\tau_{x z}\right)_{q}
\end{array}\right.
$$

The stress components generated by positive force $p$ and tangential force $q$ were as follows:

$$
\left\{\begin{array}{l}
\left(\sigma_{x}\right)_{p}=-\frac{p_{0}}{a}\left[m\left(1+\frac{z^{2}+n^{2}}{m^{2}+n^{2}}\right)-2 z\right] \\
\left(\sigma_{z}\right)_{p}=-\frac{p_{0}}{a} m\left(1-\frac{z^{2}+n^{2}}{m^{2}+n^{2}}\right) \\
\left(\tau_{x z}\right)_{p}=\frac{p_{0}}{a} n\left(\frac{m^{2}-z^{2}}{m^{2}+n^{2}}\right) \\
\left(\sigma_{x}\right)_{q}=-\frac{q_{0}}{a}\left[n\left(z-\frac{z^{2}-m^{2}}{m^{2}+n^{2}}\right)-2 z\right] \\
\left(\sigma_{z}\right)_{p}=\mu\left(\tau_{x z}\right)_{p} \\
\left(\tau_{x z}\right)_{p}=\mu\left(\sigma_{x}\right)_{p}
\end{array}\right.
$$

Parameters $m$ and $n$ were put into formula (7) and the following formulas were gained:

$$
\left\{\begin{array}{l}
m^{2}=\frac{1}{2}\left\{\left[\left(a^{2}-x^{2}+z^{2}\right)^{2}+4 x^{2} z^{2}\right]^{1 / 2}+\left(a^{2}-x^{2}+z^{2}\right)\right\} \\
n^{2}=\frac{1}{2}\left\{\left[\left(a^{2}-x^{2}+z^{2}\right)^{2}+4 x^{2} z^{2}\right]^{1 / 2}-\left(a^{2}-x^{2}+z^{2}\right)\right\}
\end{array}\right.
$$


Put parameters $\mathrm{m}$ and $\mathrm{n}$ in formula (8) and the friction parameter $\mu=0.1$ into formula (7), and then stress components generated by the positive force $\mathrm{p}$ and the tangential force $q$ were acquired. Subsequently, put the stress components into formula (6) in order to get $\sigma_{x}, \sigma_{z z}, \tau_{x z}$; finally, put $\sigma_{x}, \sigma_{z}, \tau_{x z}$ into formula (5), and gained the distribution function of the shear stress $\tau_{1}$ on the X-Z plane. Figure 11 displayed the contour line of the shear stress on the $\mathrm{X}-\mathrm{Z}$ plane, signifying that the maximum of the shear stress was $0.321 P_{0}$ at the depth of $0.6 \mathrm{a}$.

In order to better observe the variations of shear stress with depths under different contact stress, shear stresses at different depths were projected onto the Y-Z plane, and then the variations of shear stress with the depths were gained, shown in Figure 12. It was discovered that the variation tendency of shear stress from the surface to the central part of the specimens was the same as the variation tendency of hardness measured: under different contact stresses, the depth of the subsurface maximum hardness from the surface corresponded quite well to that of the maximum shear stress calculated.

\subsection{The Microstructure on the Surface Layer and the Hardening Process}

From the observation of the microstructure on the surface in Figure 7, it could be found that a thin layer of ultrafine microstructure with the thickness of 0.5 $1.5 \mu \mathrm{m}$ existed on the surface layer, generated by mechanical process where the material of the surface layer underwent severe plastic deformation. The microhardness measured under the external force of $25 \mathrm{~g}$ in the research was only about $400 \mathrm{HV}$. Although it is much higher than that of the matrix microstructure $(255 \mathrm{HV}-265 \mathrm{HV})$, the thickness of the hardened layer at least should be higher than $4 \mu \mathrm{m}$ under the load of $25 \mathrm{~g}$ based on the measurement standard of microhardness (GB/T4340.1-2009) [22]; even through the use of the minimum load of $10 \mathrm{~g}$ to measure microhardness, the minimum thickness required by this

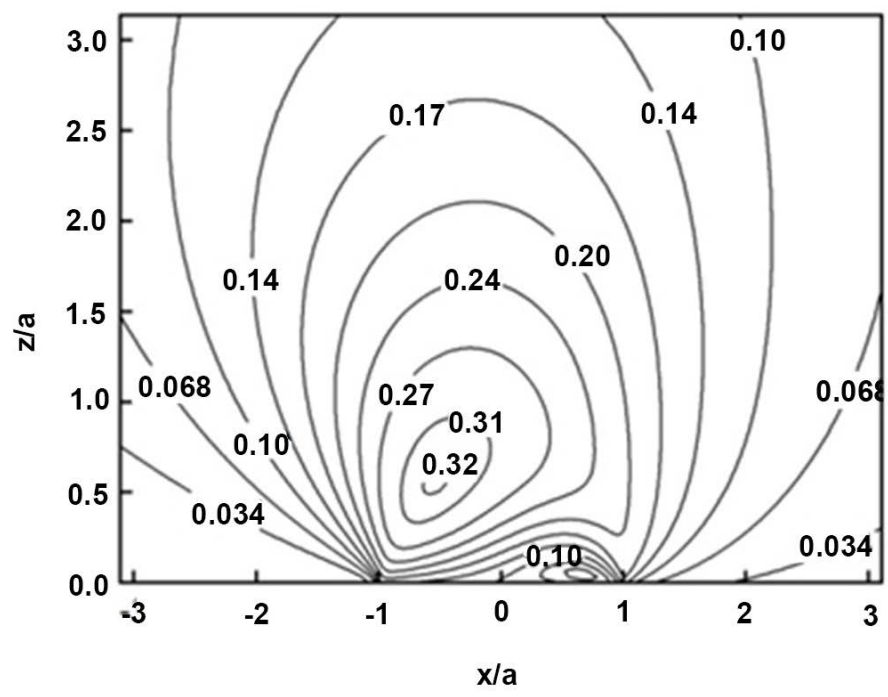

Figure 11. The contour line of the shear stress on the xz plane. 


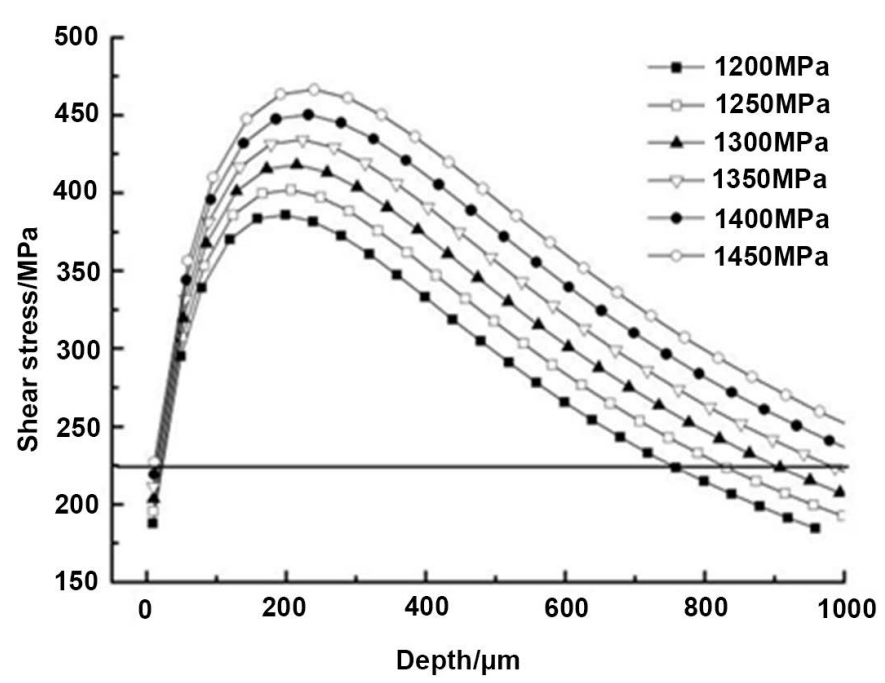

Figure 12. The relation between the shear stress and the depth under different contact stresses.

standard must be larger than the observed one $(0.5-1.5 \mu \mathrm{m})$ in this article. Therefore, the actual microhardness of this layer of ultrafine microstructure should far exceed the one measured in the experiment, which is related to the actual microhardness of the surface layer, the combining force between the surface layer and the matrix and the hardness of the matrix [23] [24]. Based on the fact that the matrix hardness of the material in the experiment was relatively low, it could be speculated that the actual hardness of this layer induced by mechanical processing would be extremely high, exerting negative impacts on fatigue properties [25]. During this investigation, it was found that this thin layer was inclined to crack and spall (seen in Figure 6), indicating that it possessed relatively high hardness.

From the results in Figure 8 and Figure 9, it could be seen that even fatigue failure specimens did not appear in the operation under laboratory conditions, the microstructure in the surface layer underwent refinement and the hardness of the surface layer was also increased, shown in Figure 10. Additionally, this type of refinement and hardening process accorded with the variation law of the shear stress calculated (displayed in Figure 11, Figure 12 and Figure 13). This meant that under the impact of contact stress, obvious plastic deformation occurred in the surface layer and dislocations inside ferrite began to be released, continually increasing the amount of dislocations. Not only could the increasing amount of dislocations elevate hardness, but could enlarge the misorientations between subgrains-eventually evolving into high angle grain boundary and refining grains. The refinement of grains also would cause hardness to increase. This evolution of dislocation structure and microstructure was immensely similar to the nanocrystallization of the mechanically-processed surface investigated by $\mathrm{Ke} \mathrm{Lu}$ and others [26] [27] —only the size of the grains during the experiment was far from being nanoscale. 


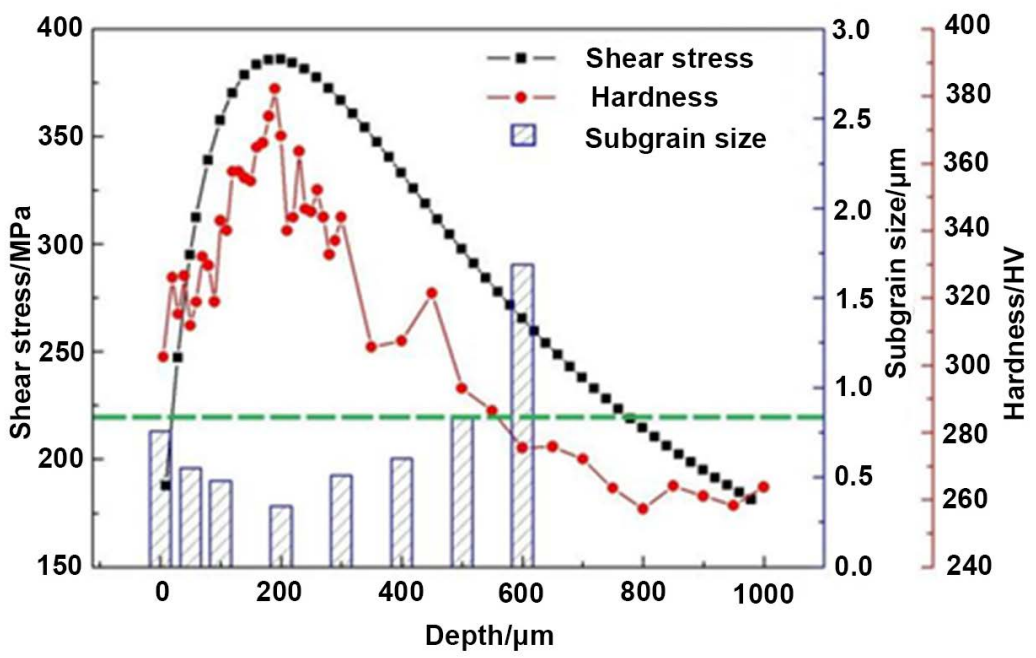

Figure 13. The relationship between the shear stress, the microhardness distribution and the subgrain size of proeutectoid ferrite on the surface layer.

Meanwhile, it could also be discovered from Figure 8 that even under fatigue limit, when proeutectoid ferrite was refined, ferrite subgrains inside pearlitic colonies underwent transformations as well-the contrast between each subgrain was enlarged, which meant that the misorientation between ferrite subgrains was increased. This phenomenon could be attributed to the theory similar to that of the refinement of ferrite subgrains: under the impact of contact stress, the ferrite inside pearlite underwent plastic deformation, dislocations inside the ferrite began to be released, and dislocations constantly moved to the subgrain boundary, enlarging the misorientation between subgrains. Since the yield strength of proeutectoid ferrite is approximately $100-170 \mathrm{MPa}$ and the yield strength of pearlite is about $600 \mathrm{MPa}$ [28], under the impact of contact stress, proeutectoid ferrite preferentially underwent plastic deformation and dislocation accumulation constantly drove the increment of dislocation density, which gradually refined grains. Nevertheless, in that the ferrite inside pearlite was limited by the enhancement of lamellar cementite, the ferrite was not inclined to deform and did not reach the limit of grain refinement-but only increased the misorientation between ferrite subgrains inside pearlitic colonies.

\subsection{The Formation and Propagation of Fatigue Cracks}

Multitudinous research [1] [8] [10] [29] indicated that main forms of contact fatigue failure on the wheel/rail surface during actual operation all resulted from the micro-roughness, falling into the category of contact fatigue caused by a crack source on the surface. In the investigation of this article, the same result was acquired under the lubricating condition (shown in Figure 3 and Figure 5). Additionally, it was found that the layer of ultrafine microstructure with high hardness and low toughness on the mechanically-processed surface layer was nonuniform. Although protruding points like peaks and valleys on the surface were worn smooth during the rolling contact fatigue experiment and hence the 
roughness was diminished (seen in Figure 5), regional spalling would take place on this thin layer and finally became the crack source under the combined impact of contact stress and additional hydrodynamic stress from liquid medium. Once the crack source formed, it would propagate towards the depths [5] [6] [7] [30] [31] [32] along the direction at a certain angle with the contact surface (about $30^{\circ}-45^{\circ}$ ) under the above-mentioned stresses (displayed in Figure 4).

During the process of crack propagation, the stress field at the tip of cracks would increase under the impact of incompressible liquid, leading the material at the tip of cracks to undergo plastic deformation. Apparently, due to the low strength of ferrite, plastic deformation tended to take place, making cracks propagate more easily; however, since lamellar pearlite possesses high strength and strong resistance to plastic deformation, it cannot be easily penetrated by cracks [28]. In certain regions, cracks penetrated lamellar pearlite and the stress field at the tip of cracks caused pearlitic lamellae to twist obviously (seen in Figure 7), displaying apparent characteristic of fatigue crack propagation and signifying lamellar pearlite held relatively strong resistance to crack propagation.

Besides, the contact fatigue experiment conducted under the condition below fatigue limit indicated that even though fatigue cracks did not appear after $1 \times$ $10^{7}$ rotations, the microstructure and the hardness at certain depths inside the surface layer did experience changes (seen in Figure 8 and Figure 10). The process of these changes could also be understood through the assistance of material regional properties proposed by Johnson and others [33]. Under the load of $1200 \mathrm{MPa}$ and $1250 \mathrm{MPa}$, though the surface and the surface layer both experienced plastic deformation, they were roughly in the shakedown limit and did not reach the extent of fatigue failure; nonetheless, when the load was higher than $1300 \mathrm{MPa}$, the surface of the material had already entered the stage of ratcheting effect, causing plastic deformation to accumulate continuously and further resulting in the formation of fatigue cracks.

\section{Conclusions}

In this article, through the rolling contact fatigue experiment, the contact fatigue property of the wheel steel used in high-speed railway under the condition of oil lubrication was investigated; in particular, great emphasis was laid on the effects of the microstructure at the outermost layer on fatigue property. The conclusions were as follows:

1) The layer of ultrafine microstructure on the original specimen surface induced by mechanical processing possessed rather high hardness and could lead to microcracks and shallow spalling during the contact fatigue test under oil lubrication, subsequently becoming the source of contact fatigue cracks under the combined impact of both contact stress and hydrodynamic pressure from lubricating oil.

2) Through the analysis of the microstructure on the surface layer, the formation and propagation of contact fatigue cracks under the condition of liquid lu- 
brication could be divided into four stages: 1) shallow spalling was generated by cracks of micrometer scale on the basis of mechanical damage on the surface; 2) the shallow spalling further expanded and evolved into the fatigue crack source under the impact of contact stress and hydrodynamic pressure from lubricating oil; 3) cracks propagated into the depths of the specimen along a certain angle with the contact surface and then formed the V-shaped cracks; 4) after the formation of V-shaped cracks, the secondary cracks formed along the direction almost perpendicular to the main cracks( $\mathrm{V}$-shaped cracks) and then expanded towards the surface, eventually causing the $\mathrm{V}$-shaped spalling.

3) Even under the impact of contact stress below fatigue limit, the microstructure in the surface layer tended to undergo plastic deformation, dislocations began to be released inside ferrite, the density of dislocations was increased, and then evolved into the stage where proeutectoid ferrite grains refined themselves, the misorientation between ferrite subgrains inside lamellar pearlite was enlarged and the hardness was increased; inside the subsurface appeared grain refinement and the hardness maximum, whose variation laws were accorded with that of the shear stress calculated. This is of great significance in delving into the effects of the microstructure and inclusions on crack formation and propagation and predicting ultra-long fatigue life during the process of contact fatigue.

\section{Fund}

This research was supported by National Key Basic Research Program of China (No. 2015CB654802) and Innovation Team Funding from Liaoning Province (2015).

\section{Conflicts of Interest}

The authors declare no conflicts of interest regarding the publication of this paper.

\section{References}

[1] Li, X., Jin, X.S., Wen, Z.F., Cui, D.B. and Zhang, W.H. (2011) A New Integrated Model to Predict Wheel Profile Evolution Due to Wear. Wear, 271, 227-237. https://doi.org/10.1016/j.wear.2010.10.043

[2] Zhong, W., Hu, J.J., Shen, P., Wang, C.Y. and Liu, Q.Y. (2011) Experimental Investigation between Rolling Contact Fatigue and Wear of High-Speed and Heavy-Haul Railway and Selection of Rail Material. Wear, 271, 2485-2493.

https://doi.org/10.1016/j.wear.2010.12.053

[3] Tatsumi, K., Mineyasu, T. and Minoru, H. (2011) Development of SP3 Rail with High Wear Resistance and Rolling Contact Fatigue Resistance for Heavy Haul Railway. JFE Technical Report, 16, 32-37.

[4] Franklin, F.J. and Kapoor, A. (2007) Modeling Wear and Crack Initiation in Rails. The Proceedings of the Institution of Mechanical Engineers, Part F: Journal of Rail and Rapid Transit, 221, 23-33. https://doi.org/10.1243/0954409JRRT60

[5] Bower, A.F. (1988) The Influence of Crack Face Friction and Trapped Fluid on Sur- 
face Initiated Rolling Contact Fatigue Cracks. Journal of Tribology, 110, 704-711. https://doi.org/10.1115/1.3261717

[6] Fletcher, D.I., Hyde, P. and Kapoor, A. (2008) Modelling and Full-Scale Trials to Investigate Fluid Pressurization of Rolling Contact Fatigue Cracks. Wear, 265, 1317-1324. https://doi.org/10.1016/j.wear.2008.02.025

[7] Fletcher, D.I. and Beynon, J.H. (2000) The Effect of Intermittent Lubrication on the Fatigue Life of Pearlitic Rail Steel in Rolling-Sliding Contact. Proceedings of the Institution of Mechanical Engineers, Part F: Journal of Rail and Rapid Transit, 214, 145-158. https://doi.org/10.1243/0954409001531270

[8] Lunden, R. (1992) Cracks in Railway Wheels under Rolling Contact Load. Proceedings of the 10 th International Wheelset Congress, Sydney, 163-167.

[9] Bogdanski, S., Olzak, M. and Stupnicki, J. (1998) Numerical Modelling of a 3D Rail RCF "Squat"-Type Crack under Operating Load. Fatigue \& Fracture of Engineering Material \& Structure, 21, 923-935. https://doi.org/10.1046/j.1460-2695.1998.00082.x

[10] Kapoor, A., Franklin, F., Wong, S. and Ishida, M. (2002) Surface Roughness and Plastic Flow in Rail Wheel Contact. Wear, 253, 257-264.

https://doi.org/10.1016/S0043-1648(02)00111-4

[11] Pal, S., Daniel, W.J.T., Valentec, H.G., Wilson, A. and Atrens, A. (2012) Surface Damage on New AS60 Rail Caused by Wheel Slip. Engineering Failure Analysis, 22, 152-165. https://doi.org/10.1016/j.engfailanal.2012.01.002

[12] Pal, S., Daniel, W.J.T. and Farjoo, M. (2013) Early Stages of Rail Squat Formation and the Role of a White Etching Layer. International Journal of Fatigue, 52, 144-156. https://doi.org/10.1016/j.ijfatigue.2013.02.016

[13] Li, S., Wu, J., Etrov, R.H., Li, Z., Dollevoet, R. and Siersma, J. (2016) "Brown Etching Layer": A Possible New Insight into the Crack Initiation of Rolling Contact Fatigue in Rail Steels. Engineering Failure Analysis, 66, 8-18.

https://doi.org/10.1016/j.engfailanal.2016.03.019

[14] Chen, Y.D., Zhao, X.J., Liu, P.T. and Pan, R.R.M. (2018) Influences of Local Laser Quenching on Wear Performance of D1 Wheel Steel. Wear, 414-415, 243-250. https://doi.org/10.1016/j.wear.2018.07.016

[15] Lian, Q.L., Deng, G.Y., Al-Juboori, A., Li, H.J., Liu, Z.M., Wang, X. and Zhu, H.T. (2019) Crack Propagation Behavior in White Etching Layer on Rail Steel Surface. Engineering Failure Analysis, 104, 816-829. https://doi.org/10.1016/j.engfailanal.2019.06.067

[16] Linz, M., Cihak-Bayr, U., Trausmuth, A., Scheriau, S., Künstner, D. and Badisch, E. (2015) EBSD Study of Early-Damaging Phenomena in Wheel-Rail Model Test. Wear, 342-343, 13-21. https://doi.org/10.1016/j.wear.2015.08.004

[17] Olver, A.V. (2005) The Mechanism of Rolling Contact Fatigue: An Update. Proceedings of the Institution of Mechanical Engineers, Part J: Journal of Engineering Tribology, 219, 313-330. https://doi.org/10.1243/135065005X9808

[18] Li, G., Hong, Z.Y. and Yan, Q.X. (2015) The Influence of Microstructure on the Rolling Contact Fatigue of Steel for High-Speed-Train Wheel. Wear, 342-343, 349-355. https://doi.org/10.1016/j.wear.2015.10.002

[19] Ministry of Industry and Information Technology of the People's Republic of China (2014) YB/T5345-2014, Rolling Contact Fatigue Test Method for Metal Materials. Metallurgical Industry Press, Beijing, 1-23.

[20] Timoshenko, S.P., Goodier, J.N. and Abramson, H.N. (1970) Theory of Elasticity (3rd ed.). Journal of Applied Mechanics, 37, 888. https://doi.org/10.1115/1.3408648 
[21] Jonson, K.L. (1992) Contact Mechanics. Higher Education Press, Beijing.

[22] (2010) GB/T 4340.1-2009 Metallic Materials-Vickers Hardness Test-Part 1: Test Method. 1-11.

[23] Cai, X., Zhang, X. and Zhou, P.-N. (1993) The Indentation Size Effect on Microhardness. Physical and Chemical Testing-Phsical Section, 29, 19-22.

[24] Cai, X. (1991) Discussion on Microhardness of Ultrafine Load and Its Application. Heat Treatment of Metal, No. 7, 48-51, 59.

[25] Yang, S.Q. (2011) Surface Finishing Theory and New Technology. National Defense of Industry Press, Beijing.

[26] Tao, N.R., Wang, Z.B., Tong, W.P., Sui, M.L., Lu, J. and Lu, K. (2002) An Investigation of Surface Nanocrystallization Mechanism in Fe Induced by Surface Mechanical Attrition Treatment. Acta Materialia, 50, 4603-4616. https://doi.org/10.1016/S1359-6454(02)00310-5

[27] Lu, K. and Lu, J. (2004) Nanostructured Surface Layer on Metallic Materials Induced Surface Mechanical Attrition Treatment. Materials Science and Engineering $A, 375-377,38-45$. https://doi.org/10.1016/j.msea.2003.10.261

[28] Garnham, J.E. and Davis, C.L. (2008) The Role of Deformed Rail Microstructure on Rolling Contact Fatigue Initiation. Wear, 265, 1363-1372. https://doi.org/10.1016/j.wear.2008.02.042

[29] Jiang, X.Y. and Jin, X.S. (2004) Influence of Liquid and Micro-Roughness between Wheel and Rail on the Fatigue Damage of Contact Surface. Chinese Journal of Mechanical Engineering, 40, 18-23. https://doi.org/10.3901/JME.2004.08.018

[30] Clayton, P. and Su, X. (1996) Surface Initiated Fatigue of Pearlitic and Bainitic Steels under Water Lubricated Rolling/Sliding Contact. Wear, 200, 63-73. https://doi.org/10.1016/S0043-1648(96)07250-X

[31] Dikshit, V. and Clayton, P.A. (1992) Simple Material Model for Water Lubricated Rolling Contact Fatigue of Eutectic Steels. Lubrication Engineering, 48, 606-614.

[32] Kaneta, M. and Murakami, Y. (1997) Effects of Oil Pressure on Surface Crack Grow Thin Rolling Contact/Sliding Contact. Tribology International, 20, 210-217. https://doi.org/10.1016/0301-679X(87)90076-4

[33] Johnson, K.L. (1989) The Strength of Surfaces in Rolling Contact. Proceedings of the Institution of Mechanical Engineers, 203, 151-163.

https://doi.org/10.1243/PIME_PROC_1989_203_100_02 